Bio - grafía. Escritos sobre la Biología y su Enseñanza. ISSN 2027-1034

Edición Extraordinaria. p.p. 681 - 688

Memorias del IX Encuentro Nacional de Experiencias en Enseñanza de la Biología y la

Educación Ambiental. IV Congreso Nacional de Investigación en Enseñanza de la Biología.

\title{
CAMBIOS CONCEPTUALES RESPECTO A GENÉTICA EN ESTUDIANTES DEL GRADO $8^{\circ}$
}

CONCEPTUAL CHANGES REGARDING GENETICS IN 8th GRADE STUDENTS

Lina Nayarid Triviño ${ }^{1}$

\section{RESUMEN}

La genética es la ciencia que estudia la transmisión de la información hereditaria de una generación a la siguiente donde el objeto de estudio son los genes, para Smith y Sims, 1992 el dominio de la base conceptual de la genética es fundamental para entender la teoría de la evolución, es por ello que se han realizado investigaciones didácticas donde se evidencia que los estudiantes tienen dificultades para entender varios conceptos sobre genética y sobre los mecanismos relacionados con la transmisión de la herencia biológica (Figini y Micheli,2005). Igualmente se presentan datos sobre la interpretación incorrecta ente la dominancia y recesividad (Heim,1991). En el presente trabajo se pretendió evidenciar los cambios conceptuales respecto a genética mendeliana. La metodología está enmarcada en el enfoque cualitativo, utilizando el análisis de los contenidos verbales de la teoría de Pozo (1992) y se usaron los talleres como métodos de recolección de información, desarrollada con la participación de 47 estudiantes del grado $8^{\circ}$ del colegio Orlando Higuita Rojas del municipio de Bogotá (Cundinamarca). Se observa que durante la intervención en el aula hubo un cambio conceptual en los estudiantes de acuerdo a Pozo y los contenidos verbales, de igual forma se pudieron evidenciar que los estudiantes lograron pasar de datos a conceptos, pero que estos tienen dificultades para construir principios acerca de los temas de genética.

PALABRAS CLAVE: Genética, cambio conceptual, contenidos verbales.

\begin{abstract}
Genetics is the science that studies the transmission of hereditary information from one generation to the next where the object of study are genes; for Smith and Sims, 1992 the domain of the conceptual basis of genetics is fundamental to understanding the theory of (Figini and Micheli, 2005). In the present study, it was observed that the students had difficulties in understanding several concepts about genetics and the mechanisms related to the transmission of biological inheritance. Data are also presented on the incorrect interpretation of dominance and recessivity (Heim, 1991). In the present work it was tried

\footnotetext{
${ }^{1}$ Estudiante de la Universidad Distrital Francisco José de Caldas; lintrivinoc@correo.udistrital.edu.co lina 9407@gmail.com

${ }^{2}$ Estudiante de la Universidad Distrital Francisco José de Caldas; camitovar18@gmail.com
} 
Bio - grafía. Escritos sobre la Biología y su Enseñanza. ISSN 2027-1034

Edición Extraordinaria. p.p. 681 - 688

Memorias del IX Encuentro Nacional de Experiencias en Enseñanza de la Biología y la

Educación Ambiental. IV Congreso Nacional de Investigación en Enseñanza de la Biología.

to evidence the conceptual changes with respect to Mendelian genetics. The methodology is framed in the qualitative approach, using the analysis of verbal contents of Pozo's theory (1992) and the workshops were used as methods of information collection, developed with the participation of 47 students of 8th grade Orlando Higuita Rojas of the municipality of Bogotá (Cundinamarca). It is observed that during the intervention in the classroom there was a conceptual change in the students according to Pozo and the verbal contents, just as it was possible to prove that the students managed to pass from data to concepts, but that these have difficulties to build principles about of genetic issues.

KEY WORDS: Genetics, conceptual change, verbal content.

\section{INTRODUCCIÓN}

La educación es un proceso continuo que se da en la interacción entre estudiantes -docentes y en concordancia con un currículo de cualquier institución educativa; hoy día es necesario que los docentes diseñen e implementen nuevas estrategias con el fin de mejorar la calidad en la enseñanza de la ciencia, siendo de gran importancia el desarrollo de cambios conceptuales en los estudiantes que les permitan la transformación de conceptos.

El Cambio Conceptual dentro de la Educación es de vital importancia como nos menciona Estrada (2014) "El cambio conceptual como esa posibilidad de sustituir, complementar o contrastar conocimientos que ya se tienen con los nuevos conocimientos que se plantean o que complementan los ya existentes, por eso y como algunos autores lo afirman los conocimientos previos o primeras experiencias son necesarios para realizar la nueva concepción científica y obtener el aprendizaje significativo buscado".(p.28)

El cambio conceptual se genera en cuanto a la reorganización de los esquemas centrales que tienen los estudiantes frente a un tópico específico, en esta medida se analizara las ideas previas de genética mendeliana frente a los talleres realizados en clase para determinar si existió un cambio conceptual en los estudiantes, ello se analizara desde la teoría de Pozo (1992) que dice: "partiendo de una distinción ya establecida en los currículos, podemos diferenciar entre tres tipos principales de contenidos verbales: los datos, los conceptos y los principios", estos son la base para el análisis de los datos recolectados y para evidenciar un cambio conceptual entre los estudiantes, y permiten ver si el estudiante ha transitado desde las preconcepciones anteriores hacia darle un significado conceptual a los fenómenos reales, para ello Pozo (1992) nos menciona que existen tres condiciones para que se produzca dicho cambio desde los contenidos verbales y son: "Un dato o un hecho es una información que afirma o declara algo sobre el mundo (...) parte de esos datos son necesarios para aprender ciencia y deben enseñarse en el aula, pero otros son de conocimiento público". La mayoría de estudiantes poseen datos acerca de genética mendeliana ya que es un conocimiento necesario en el currículo de las instituciones educativas a nivel nacional. Para poder hacer comprensible un dato se requieren conceptos donde según Pozo (1992) "Relacionar esos datos dentro de una red de significados que explique porque se producen y que consecuencias tienen (...) por lo tanto interpretar o comprender un dato es más difícil que conocerlo". 
Bio - grafía. Escritos sobre la Biología y su Enseñanza. ISSN 2027-1034

Edición Extraordinaria. p.p. 681 - 688

Memorias del IX Encuentro Nacional de Experiencias en Enseñanza de la Biología y la

Educación Ambiental. IV Congreso Nacional de Investigación en Enseñanza de la Biología.

Dentro del aprendizaje de conceptos se encuentra una red mucho más estructural llamada principios donde según Pozo (1992) "los principios serian conceptos muy generales de un gran nivel de abstracción, que suelen subyacer a la organización conceptual de un área... atraviesan todos los contenidos de esas materias y cuya comprensión plena debe ser uno de los objetivos esenciales". (Estrada, 2014).

El propósito de este proyecto es evidenciar los cambios conceptuales acerca de genética que tienen los estudiantes de grado $8^{\circ}$ a través de la implementación de talleres, tomando como referencia la teoría de cambio conceptual.

Según, María Inés Maceratesi (1999) un taller consiste en la reunión de un grupo de personas que desarrollan funciones comunes, para estudiar y analizar problemas y producir soluciones en conjunto o individuales; dentro de los talleres se destacan habilidades mentales para comprender procesos, determinar causas y elegir soluciones prácticas a los interrogantes planteados, es decir que se trata de una actividad constructiva del estudiante. Siguiendo esta línea para Ander Egg (1999) existen 3 tipos de taller: 1. Taller Total. 2. Taller Horizontal 3 Taller vertical, en este trabajo se empleara el taller horizontal donde según Egg(1999) Engloba estudiantes que se encuentran en un mismo nivel $u$ año de estudios. Este es aplicado o desarrollado en niveles primarios y secundarios. Dicho taller es de bastante importancia en la presente investigación ya que con él se evidenciara la enseñanza-aprendizaje de la genética.

En cuanto a la enseñanza de genética y el cambio conceptual Ayuso (2002) nos dice que: "Dotar a los estudiantes de un marco conceptual elemental sobre la localización, la transmisión y los cambios de las características hereditarias contribuirá a que éstos comprendan mejor el significado de ciertos fenómenos biológicos importantes, como la división celular, o la reproducción de los seres vivos" ( $p, 133)$. Esto quiere decir que para generar cambios conceptuales en cuanto al área de genética sería conveniente utilizar situaciones y ejemplos más próximos a los estudiantes como la diversidad de la clase, caracteres hereditarios familiares. . (Ayuso; 2012)

Por otra parte la selección y la naturaleza de las actividades de enseñanza deben ser lo suficientemente intencionadas, con el objeto de permitir que los estudiantes alcancen, en la medida de lo posible, los objetivos del aprendizaje (Ayuso; 2012). Para Caballero (2008) menciona que existe poca claridad en cuanto a la localización del material genético y su forma de transmisión así como una vaga comprensión de las leyes de Mendel, tema esencial para comprender la genética.

Para lograr los objetivos del aprendizaje implementaremos talleres horizontales, los cuales ayudaran a la comprensión de conceptos logrando que los estudiantes contrasten sus hipótesis en cuanto lo que saben de genética y herencia, de esta forma los requisitos del cambio conceptual se verán reflejados en los mismos y de esta manera se justifica de forma general la razón de la implementación de trabajos prácticos con los estudiantes de la institución para lograr un análisis asertivo en cuanto a los cambios conceptuales generados en los tópicos específicos que se componen en la enseñanza-aprendizaje de la genética mendeliana. 
Bio - grafía. Escritos sobre la Biología y su Enseñanza. ISSN 2027-1034

Edición Extraordinaria. p.p. 681 - 688

Memorias del IX Encuentro Nacional de Experiencias en Enseñanza de la Biología y la

Educación Ambiental. IV Congreso Nacional de Investigación en Enseñanza de la Biología.

\section{METODOLOGÍA}

Este estudio fue llevado a cabo en el Colegio Orlando Higuita Rojas, de Bogotá, con 47 estudiantes del grado octavo de Bachillerato, bajo un enfoque de tipo cualitativo, trabajando conceptos de genética mendeliana que permite entender temáticas como mutaciones, herencia genética, entre otros. Con el fin de evidenciar estos cambios conceptuales, se implementaron diferentes talleres como estrategias para desarrollar dicho cambio, además busca que los estudiantes a través de su creatividad logren elaborar diferentes casos hipotéticos respecto a los caracteres heredables, e integren este concepto en su estructura cognitiva.

El estudio se trabajó de la siguiente manera: elaboración de las encuestas (ideas previas), implementación de trabajos prácticos y recolección de datos; análisis e interpretación de resultados.

Elaboración de las encuestas (ideas previas): se realiza una primera encuesta de una pregunta ¿Qué es la herencia?, y se solicita que contesten las preguntas de la forma más completa que puedan, esto con el fin de conocer en qué nivel están los estudiantes. Con base en este cuestionario se pudo establecer cuál es el punto de referencia o de partida para entender las ideas y dificultades que presentan los estudiantes acerca de genética mendeliana y en base a estas planear las actividades a desarrollar en clase.

Con los estudiantes se realizaron talleres durante seis (6) fases, en este período se impartieron clases teóricas, divididas asi: 1que es la herencia, 2conceptos generales de gen, homocigoto,heterocigoto,cuadro de punet, caracteres dominantes y recesivos etc 3enfermedades genéticas 4 herencia en hijos (alelos dominantes, alelos recesivos) 5conceptos de clonación 6 construccion de un monstruo a través de los caracteres; todo ello se realizó bajo ayuda audiovisual, exposiciones, actividades y discusiones en clase referentes a la genética. En las discusiones de clase, el docente actuaba como guía y planteaba preguntas para orientarlos, de igual manera al finalizar cada clase se realizaba una retroalimentación de los temas vistos.

En análisis de contenido se realizó escogiendo dos estudiantes al azar y obedeciendo a la teoría de Pozo (1992) en la que se proponen pautas entre el cambio de los conceptos durante el desarrollo de la ciencia y el cambio conceptual producto de acomodar el aprendizaje de la ciencia de forma personal

\section{RESULT ADOS Y DISCUSIÓN}

Cuando se implementaron los talleres que se basaban en la resolución de problemas se encontró que los estudiantes lograban apropiarse de conceptos de genética como genes, herencia, dominancia, recesividad etc., la estrategia que se utilizó para impartir la clase se basó en una síntesis teórica del tema, en la visualización de ejemplos para afianzar los contenidos (a través de un organizador previo de contenido conceptual), y la solución de un taller (de contenido procedimental y actitudinal). De acuerdo con esto Bongarra (2010) el aula-taller se fundamenta en un aprendizaje activo, en una nueva forma de aprender que difiere de la "tradicional", donde es el alumno el que se apropia de los conocimientos, y el docente juega las veces de un coordinador u observador. 
Bio - grafía. Escritos sobre la Biología y su Enseñanza. ISSN 2027-1034

Edición Extraordinaria. p.p. 681 - 688

Memorias del IX Encuentro Nacional de Experiencias en Enseñanza de la Biología y la Educación Ambiental. IV Congreso Nacional de Investigación en Enseñanza de la Biología.

En la comparación de las tablas se puede observar el resultado obtenido con las encuestas y los talleres, permitiendo ver la evolución entre el primer concepto y la apropiación conceptual hasta la etapa final del proceso

\begin{tabular}{|l|l|}
\hline Taller ideas previas. & Taller final \\
\hline $\begin{array}{l}\text { Estudiante 1 } \\
\text { "la genética es la ciencia que } \\
\text { estudia como las } \\
\text { características de los padres } \\
\text { pasan a sus hijos y sirve para } \\
\text { observar eso" }\end{array}$ & $\begin{array}{l}\text { Estudiante 1 } \\
\text { "La genética es la ciencia que estudia las características heredables } \\
\text { de los padres a sus hijos mediante la ayuda de los genes" }\end{array}$ \\
\hline $\begin{array}{c}\text { Estudiante } 2 \\
\text { "la genética es eso que va en } \\
\text { la sangre y se pasa de padres } \\
\text { a hijos por las células" }\end{array}$ & $\begin{array}{l}\text { Estudiante } 2 \\
\text { "Es una rama de la biología que estudia la transmisión de la } \\
\text { infonotipos de los padres a sus hijos, su expresividad de acuerdo a si } \\
\text { son genes recesivos o dominantes y las posibles mutaciones que } \\
\text { se dan el dicha transmisión de información" }\end{array}$ \\
\hline
\end{tabular}

Tabla 1: ¿Qué es la genética? ¿Para qué sirve?

En el estudiante uno se evidencia un cambio conceptual respecto a la definición de la genética, ello coincide con Estrada (2014) acerca del cambio conceptual como la posibilidad de complementar conocimientos que ya se tienen con los nuevos conocimientos que se plantean, el estudiante dio en la respuesta al taller final un complemento a su respuesta en las ideas previas y la oriento al hablar de las características heredables y los genes, pero aun así no refleja un cambio de contenido según Pozo (1992) porque en su respuesta solo demuestra los datos recogidos y no hace una relación con otros conceptos para poderle dar un nuevo fondo y significado que explique como tal la pregunta. Por otro lado, el estudiante dos obtuvo un cambio conceptual al incluir en su respuesta al taller final, conceptos dados en clase que sustituyo por los que tenía anteriormente y ello le dio una mayor validez a su respuesta, esto demuestra que en el cambio de contenidos paso de tener datos en las respuestas dadas en ideas previas a conceptos ya que interrelaciono conceptos como el genotipo y fenotipo y explico con fluidez la pregunta.

\begin{tabular}{|c|c|}
\hline Taller ideas previas. & Taller final \\
\hline Estudiante 1 & Estudiante 1 \\
\hline $\begin{array}{l}\text { La A porque las hijas se parecen una a su padre } \\
\text { y otra a la madre porque la mayor al nacer } \\
\text { primero lleva más información hereditaria que la } \\
\text { menor y la segunda se cargara de más } \\
\text { información de la madre porque la información } \\
\text { del padre ya no está al tenerla su hermana }\end{array}$ & $\begin{array}{l}\text { La C. Las dos hijas tienen la misma cantidad de } \\
\text { información hereditaria, la diferencia está en que } \\
\text { existen los genes recesivos y los dominantes y } \\
\text { estos son los que hacen que los hijos se } \\
\text { parezcan a la mama o al papa demostrando así } \\
\text { los genotipos y los fenotipos de cada persona, } \\
\text { por eso es que unos nos parecemos a los papas }\end{array}$ \\
\hline
\end{tabular}


Bio - grafía. Escritos sobre la Biología y su Enseñanza. ISSN 2027-1034

Edición Extraordinaria. p.p. 681 - 688

Memorias del IX Encuentro Nacional de Experiencias en Enseñanza de la Biología y la Educación Ambiental. IV Congreso Nacional de Investigación en Enseñanza de la Biología.

\begin{tabular}{|c|c|}
\hline mayor. & y otros a las mamas. \\
\hline $\begin{array}{l}\text { Estudiante } 2 \\
\text { Es la C. Ambas tienen la misma cantidad de } \\
\text { información hereditaria pero al ser más fuerte la } \\
\text { información del padre esta se manifiesta más en } \\
\text { la mayor y al ser más fuerte la información en la } \\
\text { hija menor de la madre esta se manifiesta más en } \\
\text { su segunda hija. }\end{array}$ & $\begin{array}{l}\text { Estudiante } 2 \\
\text { La C. Ambos consena la misma cantidad de } \\
\text { información hereditaria, solo que en la hija mayor } \\
\text { los genes del padre se expresaron más y en la } \\
\text { hija menor menos pero los de la madre se } \\
\text { expresaron más. }\end{array}$ \\
\hline
\end{tabular}

Tabla 2: ¿Una pareja tiene dos hijos, de 9 y 12 años de edad respectivamente, ambas son mujeres y se dice que la mayor se parece mucho al padre y la menor que se parece más a su madre? ¿Cuál de las siguientes causas pueden explicar esto? Justifique su respuesta. a) La mayor lleva más información hereditaria del padre que de la madre, por lo que se parece más a su padre. b) La menor lleva más información hereditaria de la madre y por eso se parece más a su madre. c) Las dos llevan la misma cantidad de información hereditaria del padre que de la madre, pero en un caso se manifiesta la del padre y en el otro la de la madre.

Encontramos en la tabla 2 el cambio conceptual generado por el estudiante 1 dando respuesta a un caso hipotético, se observa una incrementación paulatina de nuevas ideas como nos menciona Barón (2009) donde se muestra un proceso de cambio conceptual de forma gradual donde se generan nuevas relaciones que permiten ir construyendo nuevos significados y de esta manera ir introduciendo una transformación conceptual. Este estudiante pasó de generar respuestas según Pozo (1992) de conocimiento público (dato), a generar una integración y organización conceptual a través de la abstracción de los contenidos que se le dieron en los trabajos prácticos.

En el estudiante dos logramos evidenciar la apropiación de términos de gen y como estos juegan un papel importante en los casos de herencia de características físicas y aunque no logra construir una respuesta estructurada acerca del problema propuesto esto según Estrada (2014) es debido a que los temas de genética no los logran asociar con lo cotidiano. Este estudiante se queda según la categoría propuesta por Pozo (1992) en conceptos ya que solo relaciona esos datos dentro de una red, pero no logra hacer una abstracción de estos.

Los resultados obtenidos coinciden con lo menciona Baracaldo (2015) donde "los estudiantes sacan buenos resultados cuando resuelven los ejercicios propuestos en los libros de texto, pero cuando se les pide justificar la función de los resultados obtenidos, los estudiantes no logran explicar para qué se utiliza realmente, lo que quiere decir que no logran construir principios sobre la genética. Por otro lado en esta investigación se evidencio que los estudiantes no comprenden al gen como la principal estructura en el almacenamiento de la información genética, sino que por su pequeño tamaño lo asocian a una parte de las células sanguíneas y desconocen como tal su función, esto coincide con Banet y Ayuso (2002) quienes mencionan que los estudiantes solo asocian la información hereditaria con los gametos y no con otras células del cuerpo. De igual forma los estudiantes tienen dificultades en la localización de los genes, ya que estos lo ubican dentro de las células sanguíneas pero no dan razón en qué lugar exactamente de estas células y 
Bio - grafía. Escritos sobre la Biología y su Enseñanza. ISSN 2027-1034

Edición Extraordinaria. p.p. 681 - 688

Memorias del IX Encuentro Nacional de Experiencias en Enseñanza de la Biología y la

Educación Ambiental. IV Congreso Nacional de Investigación en Enseñanza de la Biología.

tampoco mencionan a los cromosomas es decir que existe una concepción distante entre los genes - cromosomas ello coincide con lo que menciona lñiguez (2005) que habla acerca de que los estudiantes piensan que un determinado organismo puede tener cromosomas, pero no genes.

Se pudo establecer que los estudiantes relacionan la herencia genética con algunas células del cuerpo, pero no existe claridad en cuanto a su transmisión esto coincide con Caballero (2008) en cuanto a la confusión existente entre la genética y sus mecanismos de transmisión y se pudo evidenciar que el $30 \%$ de los estudiantes se encuentran en datos según Pozo (1992) ya que dichos estudiantes escriben un concepto vago acerca de la transmisión de la herencia mediante las células somáticas pero no existen relaciones con otros conceptos donde puedan justificar sus respuestas.

\section{CONCLUSIONES}

Se logró evidenciar que la existencia de ideas previas que tienen los estudiantes acerca de genética es producto del lenguaje común no científico o datos, cuando se implementan talleres en el aula respecto a genética y problemas de la vida cotidiana, estos logran pasar de datos a conceptos ya que generan redes conceptuales en torno a cambios fenotípicos ( cambios a simple vista), de igual forma se observó que los estudiantes presentan dificultades al construir principios ya que no logran asociar temas como gen y su función en la herencia, ello debido a las confusiones presentes en los significados de la genética en general y su relación de esta con la realidad.

Actualmente es necesario el diseño e implementación de diferentes estrategias para el desarrollo de los contenidos en el aula de clase que son inherentes a la vida cotidiana del estudiantado, es por ello que a través de los talleres horizontales se pudo demostrar que a través de ellos, se logra generar cambios conceptuales en los estudiantes y la construcción de nuevos conceptos en el aula, desde una perspectiva cotidiana; esto permite que como docentes debemos aterrizar los conceptos del aula de clase a las realidades de la vida para que de esta forma haya una mayor comprensión de los temas y no se entiendan como sucesos aislados que no cambian el plano conceptual ni social de los estudiantes.

\section{REFERENCIAS}

Ayuso, G.E. Banet, E. (2002) Alternativas a la enseñanza de la genética en educación secundaria. Departamento de Didáctica de las Ciencias Experimentales. Campus de Espinardo.

Banet, E. y Ayuso, E. (2002). Alternativas a la enseñanza de la genética en educación secundaria. Enseñanza de las Ciencias, 20 (20), 113-157.

Barón Birchenall, L.F. (2009). Introducción al estudio del cambio conceptual. Revista iberoamericana de psicología: ciencia y tecnología, 2(2),75

Egg, E.A (1999) El taller una alternativa de renovación pedagógica, Rio de la Plata: Editorial magisterio 
Bio - grafía. Escritos sobre la Biología y su Enseñanza. ISSN 2027-1034

Edición Extraordinaria. p.p. $681-688$

Memorias del IX Encuentro Nacional de Experiencias en Enseñanza de la Biología y la Educación Ambiental. IV Congreso Nacional de Investigación en Enseñanza de la Biología.

Estrada, A. (2014). Aplicación y evaluación del cambio conceptual como estrategia para mejorar la conceptualización de célula en estudiantes del grado octavo de bachillerato. Medellín, Colombia, 28

Filgini, E. y Micheli, A. (2005). La enseñanza de la genética en el nivel medio y la educación polimodal: contenidos conceptuales en las actividades de los libros de texto. Enseñanza de las Ciencias. Número extra VII Congreso.

Heim, W.G. (1991). What is a recessive allele? The American Biology Teacher, 53(2), pp. 94-97.

Iñiguez, F. (2005). La enseñanza de la genética: una propuesta didáctica para la educación secundaria obligatoria desde una perspectiva constructivista. Tesis Doctoral Universidad de Barcelona.

Pozo, J.I. (1992). Aprender y enseñar ciencia. Capitulo IV El aprendizaje de conceptos científicos: del aprendizaje significativo al cambio conceptual.

Smith,M.U. \& Sims, S.O. (1992). Cognitive development, genetics problem solving, and genetics instruction: A critica1 review, Journal of Research in Science Teaching, 29 (7), pp. 701-713

Tsui,C.Y.\&Treagust, D.F.(2005). Understanding Genetics: Analysis of Secondar Students Conceptual Status. Journal of Science Teacher Education, 44 